International Journal on Cybernetics \& Informatics (IJCI) Vol. 4, No. 6, December 2015

\title{
USABILITY OF WEB SITES ADDRESSING TECHNOLOGY BASED CASER (CLASSROOM ASSESSMENT STRATEGIES, EQUIPMENTS, AND RESOURCES)
}

\author{
Ms. Sushma Rani \\ UGC- Senior Research Fellow, (UGC-SRF), Department of Education, Banasthali \\ University, Jaipur, Rajasthan, India.
}

\begin{abstract}
Global advancements, competitions and economic growth have lead to a drastic change in the technological world. The impact of technology both individually as well as collectively changed our life significantly. Nomatter whether it is commercial, transportation, banking, political, or educational field technology has done wonders in all ways. With the leaps and bounds in technological field educationists still make efforts towards new achievement and goals especially in the field of teaching-learning worlds also. If we talk about today's classroom conditions, we are still lagging behind in many aspects. We are not upto mark or update. So there is a need of adoption and inclusion of ICT and technology resources to be linked to our curriculum system. The role of teacher is quite important in molding shape of our coming generations and modern society. The teacher should make use of innovative devices and strategies while teaching in the classroom situations. The teaching-learning without innovations and technological based devices is meaningless unless we strengthen our whole educational system in terms of technology-based teacher's professional development through in-service or pre-services trainings, incorporation of latest electronic gadgets and devices in teaching-learning system etc. Thus, this paper focus on the universal design for learning practices for classroom testing and assessment practices, which is designed to minimize errors, adverse consequences, and unintentional actions to assist students in using them safely and efficiently. This paper has directed about the perceptions about the usability of web sites addressing technology which includes the new technologies, approaches, strategies and techniques to be adopted in the classroom for strengthening the potential and competencies of the students. The main objectives of the paper are- (1) To find out the latest techniques, tools and technology based on the classroom assessment and resources. (2) To find out the usability of the websites addressing new technologies and strategies. (3) To make students understand about technological usage for enhancing motivation and feedback thereby reducing errors and mistakes. For this research paper, the researcher consulted various conceptual research frameworks, reviews and trends in studies related to the use of web-sites enhancing technologies, strategies, equipments and resources. The results of the study highlighted major concerns in order to monitor the technology proficiency of the students, one must use multiple methods for presenting the instruction; use multiple assessment formats and tools to support one towards academic progress. Thus, the teachers, educators, stakeholders all have to monitor the technology-based curriculum process supporting assessment and evaluation tools, techniques and resources.
\end{abstract}

Thus, it directs about the perceptions about the usability of web sites addressing technology-based CASER (Classroom assessment strategies, equipments, and resources), relying on the ICT based web-based tools and applications, which includes the new technologies, approaches strategies and techniques to be adopted in the classroom for strengthening the potential and competencies of the students to meet the global challenges for future-oriented education.

DOI: $10.5121 /$ ijci.2015.4601 
International Journal on Cybernetics \& Informatics (IJCI) Vol. 4, No. 6, December 2015

\section{KEYWORDS: -}

Websites based technology, CASER (Classroom assessment strategies, equipments and resources), ICT (Information and Communication Technologies), TSER (Technology-based strategies, equipments and resources).

\section{INTRODUCTION}

The technology toady plays a crucial role in the every spheres of life like private, commercial, business, defense, or education is most crucial field among all these. With the advent of latest technology, we found that in each and every second new technology, either in the form of hardware or software is being invented. The new emerging trends in technology has made our life quite easier, efficient and effective one. Thus, this paper addressing about the various websites addressing technology based CASER (Classroom assessment strategies, equipments and resources) in detailed for strengthening the potential and competencies of the students.

It the education, which is consider as the foundation stone for the execution and implementation of various desirable process. And proper execution and implementation of whole process can be carried out by monitoring the learning goals using variety of formal and informal means. The monitoring includes both types of "In-Action" and "Reflection-on-Action". The term "on action" refers to the student's performance in their formal assessments, while the "in-action" refers to one's day-to-day activities in the classroom.

Assessment and evaluation are the part of the monitoring, which makes ongoing modifications in the behaviors of students as well as in the teaching-learning strategies. Also, the teachers design, develop and evaluate authentic learning experiences and assessments incorporating contemporary tools and resources to maximize content learning in context and to develop the knowledge, skills, and attitudes among the students. The research paper focuses on incorporating a variety of appropriate technology-based resources for assessing learning into instruction.

\section{OBJECTIVES OF THE STUDY}

- To make student's to use application web-sites addressing technology-based classroom assessment strategies, equipments and devices for instruction and learning assessment.

- To make student's to use technology applications like using web-based resources, strategies and equipments to communicate student performance.

- To make student's to use data from multiple measure, web-sites addressing technologybased classroom assessment strategies, equipments and resources to assess their utilization towards technology usage.

- To make students understand about technological usage for enhancing motivation and feedback thereby reducing errors and mistakes. 


\section{ASSESSMENT AND EVALUATION TECHNIQUES}

Assessment is an important part of learning process. Assessment is meant "for requiring students to analyze, synthesize, and evaluate information that incorporates relevant facts and data and that requires students to reflect on and interpret their own understandings that will help one to limit sharing of answers using technological web-based classroom strategies, equipments and resources". Assessment reform Group, 1999, p.7, "according to classroom assessments that promote learning by involving sharing learning goals, self-assessment skills, helps one to know and recognize the standards for which they are aiming, provides feedback that leads to students recognizing their next steps and how to take them further, and reflecting on assessment data etc. with a belief that every student can improve.

Besides this, teacher can engage students in assigning the projects, models, tasks, simulations, that allowed one to practice the steps of an experiment before demonstrating one's understanding on an exam. The formative assessment can include video-taped performance, electronic journals, checklists, and rubrics, allows one to practice or checks one understanding before being evaluated on the 'big test'.

Assessment data can be used to assess students in terms of their evaluation by means of student's monitoring through formative assessments and evaluation through summative assessment. Today the classroom data analysis can be tacked using various CASER (Classroom assessment strategies, equipments and resources), for more sophisticated analysis of the data. One of the tremendous benefits of using technology in classroom activities is that teacher may have an easy, flexible and tremendous access to data as student's data.

\section{Objectives}

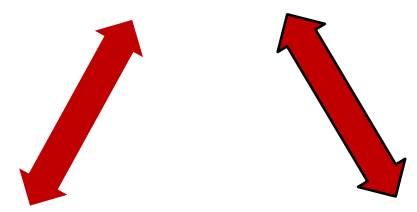

\section{Activities}

Assessment

Fig. (i) - Alignment among objectives, activities and assessment.

\section{WHY WE NEED TSER (Technology-Based Strategies, Equipments and Resources)?}

Technology is the backbone of the advanced education that facilitates teaching and testing process for teachers, students and various stakeholders. 
International Journal on Cybernetics \& Informatics (IJCI) Vol. 4, No. 6, December 2015

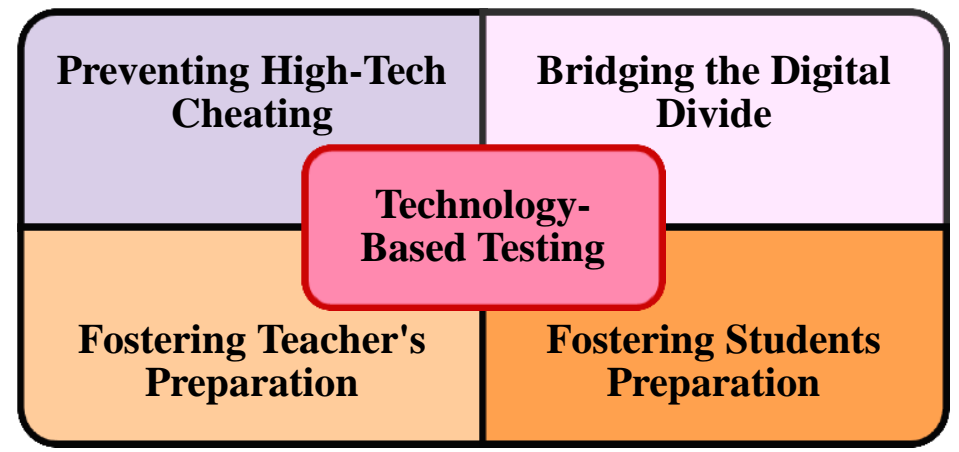

Fig. (ii) - Concerns needs with technology-based strategies, equipments and resources.

Thus, greater access to wide variety of student's data provides more opportunities for one to make better-informed about the instruction. One advantage of TSER technology evaluation tool is that teacher can analyze the performance data of students but digital technologies promotes easy, flexible and quick access to a wide range of data thereby analyzing, simplifying and reporting the data. Also, the digital tools and devices such as books, electronic online portals, lesson plans and grade books also provide state-mandated performance standards.

\section{CASER (Classroom Assessment Strategies, Equipments and Resources)}

It is important to know the student's proficiencies for the better execution and implementation of the appropriate learning activities and assessments. We have many classroom technologies that generate good yield teaching-learning process. According to Elementary and Secondary Education Act, "The latest reauthorization called No Child Left Behind (Pub. L. No. 107-110), specifies that all students entering high school to be technologically literate". But it does not fulfill its criteria till date, thus to make students crossing digital divide, we must strengthen the programs that offer assessments, evaluation, and guidance about demonstrating their proficiency skills. Below are the overview of some assessment based strategies and resources for making classroom teaching-learning process as digitalized one.

Online Resources - The evaluation of the students can be evaluated from the online resources. Assessment formats - The assessment formats can be defined in four broadly defined groups: forced-choice assessments, open-ended response assessments, performance-based assessment and project-based assessment.

- Forced-Choice assessments involves both instruction and assessment, mostly using electronic test items banks- multiple-choice, true/false, matching and fill-in-the blank question formats using in large-scale exams. The format includes question and answers by filling in the appropriate "bubbles" on a form that can be read by a test scanner. The new technology format includes the use of forced-choice items using wireless responder via infrared or radio frequency.

- Open-Ended assessments are used for demonstrating student's higher order cognitive skills such as application, synthesis, demonstrative creation etc. It includes participation 
International Journal on Cybernetics \& Informatics (IJCI) Vol. 4, No. 6, December 2015

in online communications via threaded discussions, e-mail, or even chat software or using video, graphics, media to incorporate students for text-based entries.

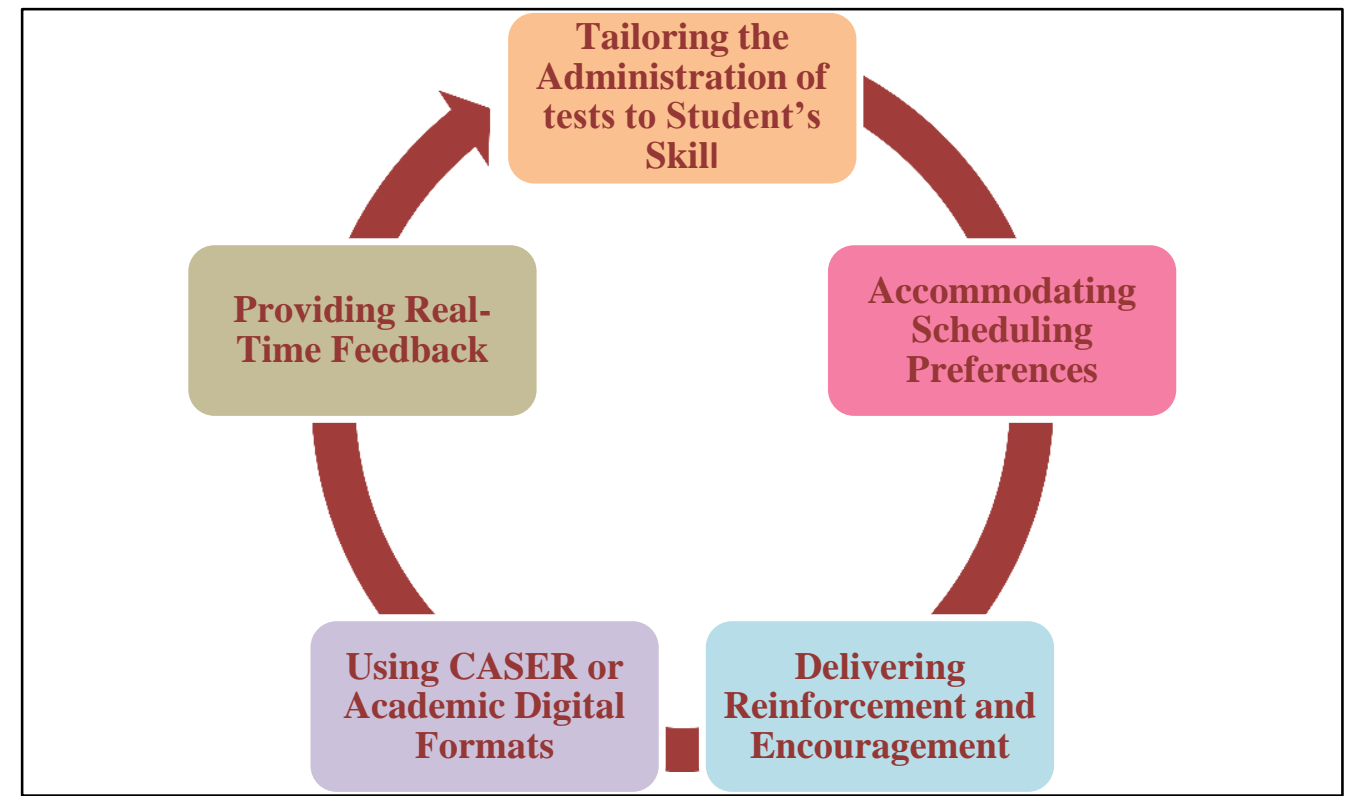

Fig. (ii) - Classroom Testing and Assessment using Technology-Based Testing (CASER)

- Performance-Based assessments are used to develop mastery through performance in all content-area. It supports oral communication skills or the development of psychomotor skills. The Performance- assessment may be used to capture or to record student's progress in the form of recording student's assessment using digital video or PDA's. Both informal and formal observations can quickly be added, accessed and recorded using handheld and laptop computers.

- Project-Based assessments are most oftently used to support problem-based learning, which is linked to a term called "Authentic Assessment", which describes higher-order thinking skills, such as problem identification, selecting and monitoring strategies for solving the problem, applying knowledge, and evaluating the success of one's efforts. In Performance-based assessment students may make use of digital media for wiring proficiency using word processing and layout software to create brochures or newspapers. Navigation and GPS devices are also used to measure the dimension for generating scale drawing.

\section{WEBSITES \& RESOURCES ADDRESSING CASER}

The Performance and Project-based assessment includes incorporate (i) Concept map (ii) Simulations (iii) Portfolios and work samples.

- Concept Maps- "Concept maps are the geographical tools for organizing and representing knowledge. One can use the concept maps to access prior knowledge, to organize and represent current knowledge and to explore new information and 
International Journal on Cybernetics \& Informatics (IJCI) Vol. 4, No. 6, December 2015

relationships. Concept maps are is widely available for facilitating the process and variety of map templates including Venn diagrams, plot outlines, timelines, lab reports etc. Creating a concept map involves identifying the important concepts in a domain of knowledge, arranging those concepts spatially, identifying relationships among the concepts, and labeling the nature of the relationships among those concepts for manipulation of information."

(i) Simulations - Simulations are the tools to provide simplifies version of the phenomena, environment that allows students to manipulate, to interact variables and observe the effects. For example microworld, which allows learners to manipulate, interact, explore, and experiment with specific phenomenon in an exploratory learning environment. It also supports one to manipulate and observe the effects in one's own actions.

(ii) Portfolios and Worksamples - There are two types of portfolios for assessment one is called a dossier, process, or document portfolio that shows student's proficiency over time. And second is the showcase portfolio contains sample of exemplary work. "The latter form of portfolio is common for assessing entry into a program, called as (AP) Advanced placement Studio Art General Portfolio programs, generally used by the college board, that combines student art work, photographic slides, and a written student reflection to determine whether student applicants receive college credit for their art skills. Portfolios incorporating word processing, database, spreadsheets, and several multimedia applications that can be posted on web using HTML, graphics, video, and other formats."

(iii) Checklists- Checklists are a simple ways to score the observation or demonstration of a skill. It can be factual recall skills or more complex skills involving analysis and evaluation. One can create a simple yes-no checklist in which the parameter or skill one is looking for is deemed either present or not. Some checklists may be available for use on PDAs and tablet computers that allow one to enter data onscreen with a stylus. It is one dimensional technique only.

(iv) Rubrics- According to Cennamo S. Katherine \& Ross D. John, "Rubrics are common methods for assessing performance-based assessment projects, especially supported by the technology. It indicates three-four-or five-point scale manageable, depending on the complexity of the task, projects, or performance to be scored. Rubrics can be analytic or holistic. An Analytic rubric breaks the assessment down into components categories ex- an analytic rubric for a student history presentation may include categories about accuracy of information , proper grammar or spelling, writing style, as well as elements of design. A holistic rubric may have description that touch on each of these elements but it does not break them down into separate rating scales per category". ${ }^{1}$ 
International Journal on Cybernetics \& Informatics (IJCI) Vol. 4, No. 6, December 2015

(v) Tools, Resources, and Assessment Software- Besides all these, there are enough more tools and resources supporting the assessment and evaluation process in teaching-learning process. For example- the electronic gradebooks, stand-alone gradebook software may allow one to print progress report of the whole class in few minutes, whereas on-line gradebooks can provide reports on-demand. On-line student information system (SIS) promotes the records of student's attendance, commutative and longitudinal data as well as helps to identify the specific individual differences too.

(vi) One can use wireless devices handheld devices such as PDAs etc. to access student's information system, to indicate class, transportation schedules, and to provide link to cafeteria and health records etc.

\section{TECHNOLOGY-BASED TSER}

There are various technologies and resources for fostering the creativity of the both students i.e. normal students as well as the inclusive students. It guide students in multi- ways through writing process, aid them in composing written responses, test-items etc. (MacArthur, 2009). Following are various tools and resources to make students best use of technology-based web-sites, resources and equipments in the present teaching-learning process.

- Word Processing- Words Processing can make it easier to compose and revise written responses and minimize handwriting problems, so that one can produce complete, organize, and legible essays (Mac Arthur, 2009). Many of these programs include

- Directions and menus that is easy to read and follow.

- Prompt students using pictures and cues and simple keystrokes using spell checkers, word cueing and prediction applications.

- Provide students access to electronic dictionaries, thesauri, and glossaries that can guide them in making varied word choices.

- $\quad$ Prompting and verification to help students save files (Hetzroni \& Shrieber, 2004).

- Electronic Dictionaries, Glossaries and Thesauri - The students can be benefitted from using the Electronic Dictionaries, Glossaries and thesauri which can help one understanding and define words or identify synonyms and other words to use in writing responses. Many of these programs include multimedia such as animations, 3-d visuals, colorful graphics and audio pronunciations to help students understand and learn word meanings and determine appropriate alternative words and phrases, useful especially for the students who are English language learners. It also supports various features like text organizations, word usage, and grammar punctuation assistance resources.

- Technological Resources and Tools - The technological resources and tools support both teacher s and students work electronically using

- Submit test-items electronically

- Receive immediate detailed feedback concerning test-item's content style, word choices, organization, mechanics and conversations.

- Use feedback to revise the test-item responses. 
International Journal on Cybernetics \& Informatics (IJCI) Vol. 4, No. 6, December 2015

\section{TSER with reference to Special Education}

Technology has the potential to deliver a range of presentation mode testing accommodations. It provides students with choices about the ways in which the test directions and items are presented to them. Using technologies students can perform tasks according to one's own pace and interest. The following are the ways in which the students can be benefitted from the technology-based testing equipments, strategies and resources. Students can

- Access links to electronic resources such as dictionaries, glossaries, and the sauri, strategy reminders, and pop-up definitions and translations.

- Highlight text and makes notes to guide them, perform cognitive skills based tasks like drawing, and responding to questions.

- Adjust text, images, and backgrounds in terms of print sizes, colors, fonts, spacing and layout.

- Control the pace of the sequences of test administration, in which the items are presented, and the number of items that can be appeared on the screen.

Technologies can be used to tailor the presentation of the text items and directions that may be helpful for the students with reading difficulties, students with sensory difficulties, and students with limited English language learning.

\section{Students with Reading Difficulties}

The students with visual and reading disabilities can benefit from a range of technologies that presents test directions and items orally. These technologies include screen or text readers, scanners, and optical character reading systems (OCRs), which allow text and visuals to be presented with audio. It supports low-tech devices that can facilitate students reading.

- Screen and Text Readers- Screen and text reader allow students to hear test directions an items read aloud to them including audio descriptions of visual images.(Hasselbring \& Bausch). These programs which can read the text aloud in different voices and languages provide students with various ways to search for or highlight words, sentences, and paragraphs that can be read aloud to them. Many of its programs may support the students to customize according to the individual preferences, by allowing them to .

- Control the pitch, and volume of the speech.

- Create pronunciation dictionaries.

- Have text digitally highlighted on the computer screen as it is read aloud to the students.

- Screen Reading Programs- The screen reading programs can be programmed to provide students with the visual impairments with verbal descriptions of images, pictures and graphics. For ex. WebAnywhere (webanywhere .cs.washington.edu.) is a free online self voicing screen reader that can be used with all types of computers to convert online text, graphics, and photographs to an audio file that is orally presented to the students. 
International Journal on Cybernetics \& Informatics (IJCI) Vol. 4, No. 6, December 2015

- Text- Scanners and OCRs- Test -Scanners and OCRs can be used by the teachers to effectively present the test-items in front of the students using speech reading capabilities. It includes one to scan sentences, words in a test directions and items and control according to individual interests by scanning the text items to be read, defined, spelled, or displayed in various character sizes. The various programs may include the dictionaries and thesaurus entries, that can be translate into variety of languages, especially for the English language learners. It supports one to

- Prepare valid and accessible tests.

- Scan of test-items to store them in any digital device like computers.

- $\quad$ Use OCRs to read tests aloud in to the students.

- Low-Tech Devices- The low-tech devices, which are usually inexpensive, nonelectronic, homemade and readily available, can be sued to facilitate the presentation of tests to the students with reading difficulties. Line guides or masks such as reading rulers or index cards, can assists students who have difficulty tracking and maintaining their place on a line. For ex. The Visual Tracking Magnifier (www.coil.co.uk) is a small handheld device that assists students in reading and maintaining their place by magnifying a line of text and providing transparent overlays that modify the background colors of pages. (Thompson et al., 2005).

2. Students with Sensory Disabilities- The various web-base addressing technology strategies and equipments may help the students with sensory disabilities to access test directions and items successfully. For ex. Visiprint (www.visiprintsoftware.com) offers a range of software programs that help one to prepare documents that can be tailored to different need and preferences students with visual impairments. The students with sensory disabilities can be benefitted using the following technologies-

- Screen Magnification and Contrast, can be used with font enlargement programs and technologies with zooming facility in on test item.

- External magnification devices support one to adjust technology-generated text and graphics to an appropriate size, font, color, and contrast.

- Programs providing audio descriptions of visual images.

- Using Flicker-free monitors with high monitors and contrast.

3. English Language Learners- Technology-based testing web-sites, resources and equipments can be used to present test items to English language learning students. The technologies can used to make students to take tests administered in one's proffered language, and to access bilingual dictionaries, glossaries, and thesauri and pop-up translations. For ex- Quicktionary (www.easytranslators.com/factfile/wizcom.htm) is a pen-like device that scans text in one language and translates it into another language. It may use the handheld talking translators or translation software programs that convert text from one language into another.

4. Students with Motor Difficulties- The technology supports various programs with resources and equipments to support students with motor-difficulties. The students with sensory motor difficulties needs alternative methods to access technology such as adapted switches, scanning systems, joysticks, headbands, and sip and puff systems, etc. (Dell et 
International Journal on Cybernetics \& Informatics (IJCI) Vol. 4, No. 6, December 2015

al., 2008). The students may use the in-built accessible features such as on-screen keyboarding, touch screens, visual and auditory warnings and highlighted mouse visibility and movement. (Dell et al., \& Neal \& Ehlert, 2006).

- Stick keys, which can be used so that one key press cause the technology to take actions that are associated with the multiple keys being pressed simultaneously. .

- MouseKeys, which allows students to direct the mouse pointer with one finger, a mouthstick, or a headpointer by using the numeric keypad to move the mouse pointer.

- Taggelkeys, which use a beeping sound to alert students when certain features are activated such as the lock keys NUM LOCK, CAPS LOCK, or SCROLL LOCK.

- Filterkeys, which contain a variety of features reaklted to adjusting the key board response time and dealing with inadvertent pressing of keys.

- Repeatkeys- which provides students with control over whether repeated key strokes are converted into computer actions and allow students to adjust the repeat start time and rate.

- Bouncekeys, which allows students who bounce when activating or releasing a key to access only one action or keyboard character.

5. Other Technologies- There are other technologies also which increases the student's with different-needs and capabilities to enhance their proficiency in a particular field. These technologies are the Augmentative communicative systems, Braille writers, pointers, electronic dictionaries, and thesauri and digital recorders that can help the students who find responding orally and in writing challenge. (Dell et al., 2008). Talking calculators, transistors, software programs, and personal digital assistants (PDAs) can be helpful for students who have the conceptual understanding to complete items bat lack in memory skills to remember math computations, facts or word definitions. (Bouck \& Bouck, 2008).

\section{SUGGESTIONS}

ISTE NETS-T Standard 2 supports one to "design, develop, and evaluate authentic resources to maximize content learning in context and to develop the knowledge, skills, and attitudes identified in the NETS-S.” Institutions must provide students with multiple and varied formative and summative assessments aligned with content and technology standards to enable them to use resulting data to inform learning and teaching process. The following are the suggestions towards the best usability of the classroom assessment strategies, equipment and resources.

- Parents, community members, business industry personnel can help support students learning in the classroom by sponsoring or participating in virtual- field trips. Or telementoring opportunities. As the field trips are the $21^{\text {st }}$ century's version, it makes students best use of audio, video, or web-conferencing tools to interact with professionals synchronously and even one can "tour" business, museums, galleries, or other sites at their convenience using images, animations, and video compiled on websites.

- Teachers, educators must have communication with the students, helping them become aware of their progress and communicate data from groups of students i.e. class, school, 
International Journal on Cybernetics \& Informatics (IJCI) Vol. 4, No. 6, December 2015

state, or national performance data, giving students the opportunity to monitor and evaluate their learning by comparing themselves to established norms.

- The educational institutions must access to up-to-date hardware, software, and connectivity with the meaningful, high-quality, and cultural responsive content and the opportunity to contribute that content.

- There must be provision to access to educators who know how to use digital tools and resources, supports also systems sustained by leaders with vision and support for change via technology.

- Students can interact with experts in a variety of career roles when parents and community members volunteer in schools, either virtually or face-to-face. These programs also provide an opportunity for students to develop a greater awareness of the importance of school within a larger context, whether the local or global community.

- Students must adopt an attitude towards e-learning, on-line learning, collaborative and virtual learning, which can benefit them from the increased opportunities for practice and reinforcement that extended learning, opportunities can provide. These opportunities may include increased accessed to resources, including technology resources, websites addressing technology-based classroom assessment strategies, equipments, and resources as well as access to people, oneself, students or other

- Educational institutions must access to extended learning opportunities both in formal or informal form, where not only students but parents and community members also share school-based physical and virtual spaces, including hardware, software and networking. Thus, by exploring the technological tools, devices and strategies we can have broader access and larger learning opportunity for huge mass thereby promoting 'lifelong learning' among various stakeholders.

- Initiatives towards "open classrooms" must be taken into consideration by incorporating pods, laptops, computers, mobiles or online learning stations into the current classroom environments.

- Students must provide access to technology after school hours through laptops, computer labs, online libraries, media and technological resources established for students, teachers, parents and community members etc.

- Provision of shareware and freeware software in the educational institutions where, the shareware software allows one to preview the software for a limited times and it requires the purchase at minimal cost. And freeware software has no cost, and these softwares require individual registrations or limit the number of copies. The freeware software is also called sometimes as the spyware. 
International Journal on Cybernetics \& Informatics (IJCI) Vol. 4, No. 6, December 2015

\section{CONLUSIONS}

Assessment is a term used for evaluating and monitoring student's achievement in different domains of education for evaluating their academic progress. From above, we concluded that educational institutions must use variety of formal and informal data for instructional decisions in the educational process. In order to monitor the technology proficiency of the students, one must use multiple methods for presenting the instruction; use multiple assessment formats and tools to support one towards academic progress. Thus, the teachers, educators, stakeholders all have to monitor the technology-based curriculum process supporting assessment and evaluation tools, techniques and resources. Assessment data also help one to determine the efficiency of one's own instructional choices including the selection of technology-based resources. Thus, teacher must know whether how one can teach, with or without digital technology, which is effective in helping, students learn the intended contents properly and effective.

\section{REFERENCES}

[1] Cennamo S. Katherine \& Ross D. John (2010). Technology Integration for Meaningful Classroom Use. Wadsworth Cengage Learning, Nelson Education Ltd, U.S.A.ISBN- 13:978-0-495-83410-6

[2] Cuban, L., Kirkpatrick, H., \& Peck, C. (2001). High access and low use of technologies in high school classrooms: Explaining an apparent paradox, American Educational Research Journal, 38(4), 813-834.

[3] Fullan, M. (2001). The new meaning of educational change (3rd ed.). New York, NY: Teachers College Press.

[4] Information on the WorLD programme is taken from the World Links for Development Website: http://www.worldbank.org/worldlinks/english/html/backgrnd.html. May 131999.

[5] Mumtaz, S. (2000). Factors affecting teachers' use of information and communications technology: A review of the literature. Journal of Information Technology for Teacher Education, 9(3), 319-342.

[6] No Child Left Behind Act of 2001, Pub L. No. 107-1105. (2001).Washington, DC: U. S. Congress.

[7] Roward, C. (2000). Teacher use of computers and the Internet in public schools. Washington, DC: National Center for Education Statistics. Retrieved on October 6, 2008, from http://nces.ed.gov/pubs2000/2000090.pdf

[8] Salend J. Spencer (2009). Classroom Testing and Assessment for All Students. Corwin Sage Publications. U.S.A. ISBN- 978-1-4129-6643-6.

[9] Smerdon, B., Cronen, S., Lanahan, L., Anderson, J., Iannotti, N. \& Angeles, J.(2000). Teachers' tools for the 21st century: A report on teachers' use of technology. Washington, D.C.: National Center for Education Statistics, U.S. Department of Education.

[10] Vannatta, R. A., \& Fordham, N. (2004). Teacher dispositions as predictors of classroom technology use. Journal of Research on Technology in Education, 36(3), 253-271. 